\title{
FERMENTAÇÃO SUBMERSA UTILIZANDO Saccharomyces cerevisiae NA PRESENÇA DE AFLATOXINA B
}

\author{
M. A. de CARVALHO SILVELLO ${ }^{1}$, P. R. RESCHKE ${ }^{1}$, T. S. de LIMA ${ }^{1}$, R. B. KRAUS ${ }^{1}$, A. \\ C. P. FELTRIN; J. GARDA BUFFON ${ }^{1}$ \\ ${ }^{1}$ Universidade Federal do Rio Grande, Escola de Química e Alimentos \\ E-mail para contato: gutasilvello20@gmail.com
}

\begin{abstract}
RESUMO - Este trabalho teve como objetivo avaliar os parâmetros cinéticos de crescimento, conteúdo proteico extracelular e atividade específica da enzima peroxidase produzidos pela levedura Saccharomyces cerevisiae durante cultivo submerso na presença da Aflatoxina $\mathrm{B}_{1}$. A fermentação alcoólica foi realizada em Erlenmeyer de $250 \mathrm{~mL}$, contendo $170 \mathrm{~mL}$ de meio de cultivo YPD, adicionado $6,66 \%(\mathrm{v} / \mathrm{v})$ do inóculo da levedura Saccharomyces cerevisiae. O cultivo foi conduzido durante $96 \mathrm{~h}$, mantido a $26^{\circ} \mathrm{C}$ sem agitação. Os ensaios foram realizados na presença e ausência (controle) de aflatoxina $B_{1}$ na concentração de 1 $\mu \mathrm{g} / \mathrm{mL}$. A amostragem foi realizada no tempo zero e a cada $24 \mathrm{~h}$ para avaliação do $\mathrm{pH}$, concentração celular, concentração proteica e atividade da enzima peroxidase. Em cultivo submerso na presença da micotoxina foi observado um aumento na velocidade específica de crescimento (15\%), maior conteúdo de proteínas extracelulares (19\% superior) em $72 \mathrm{~h}$ de processo fermentativo e maior atividade enzimática específica da peroxidase. Estes resultados confirmam a sensibilidade da levedura frente a toxicidade da aflatoxina $\mathrm{B}_{1}$, contaminante ocorrente em cereais utilizados em processos fermentativos.
\end{abstract}

\section{INTRODUÇÃO}

As micotoxinas são metabólitos secundários produzidos por diferentes tipos de fungos (CARÃO et al., 2014). Dentre elas, pode-se destacar a Aflatoxina que é produzida pelo gênero Aspergillus, principalmente pelas espécies A. flavus e A. parasiticus (OLIVEIRA et al., 2001). A aflatoxina é capaz de causar efeitos tóxicos em animais e humanos, hepatotoxicidade, nefrotoxicidade, propriedades carcinogênicas, imunotoxicidade e dermatotoxicidade (KLOSOWSKI e MIKULSKI, 2010; BOLECHOVÁ et al., 2015), entrando na dieta dos mesmos por meio de contaminação, direta ou indireta, de cereais e grãos (CARÃO et al., 2014). São conhecidos 18 compostos designados pelo termo de aflatoxinas, sendo que os principais tipos de interesse médico-sanitário são identificados como $B_{1}, G_{1}, B_{2}$ e $\mathrm{G}_{2}$. A estrutura química dessas micotoxinas é similar, apresentando um núcleo central cumarínico ligado a uma estrutura bi-furanóide. A aflatoxina $\mathrm{B}_{1}\left(\mathrm{AFLA}_{1}\right)$ é frequentemente encontrada em cereais e apresenta o maior poder toxigênico (CARÃO et al., 2014, OLIVEIRA et al., 2001).

A resolução RDC nº 07/2011 da Agência Nacional de Vigilância Sanitária (ANVISA) dispõe sobre os Limites Máximos Tolerados (LMT) para micotoxinas em alimentos e 
estabelece como $5 \mu \mathrm{g} / \mathrm{kg}$ o LMT para aflatoxinas $\mathrm{B}_{1}, \mathrm{~B}_{2}, \mathrm{G}_{1}$ e $\mathrm{G}_{2}$ em cereais, produtos de cereais, incluindo a cevada malteada (BRASIL, 2015). Além dos danos à saúde humana e animal, os prejuízos econômicos causados pela presença da aflatoxina em cereais podem ser severos (MALLMANN, SANTURIO e WENTZ, 1994).

As micotoxinas presentes nos grãos utilizados como matéria-prima de alimentos podem ser sintetizadas durante o período de pré ou pós-colheita, concomitante a fatores de estresse. Além de causarem alterações nos processos fisiológicos de organismos superiores, as micotoxinas podem afetar o metabolismo de vários micro-organismos, como a levedura Saccharomyces cerevisiae (KLOSOWSKI e MIKULSKI, 2010), largamente empregada na produção de cerveja. A ocorrência de micotoxinas em cereais utilizados na produção de desta bebida é frequentemente relatada, e a contaminação pode ocorrer em vários estágios do processo. Em consequência da estabilidade térmica das micotoxinas e de sua solubilidade parcial em água, estas podem ser transferidas do malte ou cereais adjuntos à bebida (RODRÍGUEZ-CARRASCO et al., 2015). Desta forma, é imprescindível a identificação desses contaminantes bem como a avaliação do efeito da sua presença nas características físico-químicas e bioquímica relacionadas ao estresse celular da levedura Saccharomyces cerevisiae.

Neste trabalho foram avaliados os parâmetros cinéticos de crescimento, conteúdo proteico extracelular e atividade específica da enzima peroxidase produzidos pela levedura Saccharomyces cerevisiae durante cultivo submerso na presença da Aflatoxina $\mathrm{B}_{1}$, visando detectar os efeitos da contaminação micotoxicológica durante fermentação alcoólica.

\section{MATERIAIS E MÉTODOS}

A fermentação submersa foi realizada em Erlenmeyers de $250 \mathrm{~mL}$ contendo meio de cultivo YPD como substrato, onde sua composição foi de $1 \%$ de extrato de levedura, $2 \%$ de glicose e $2 \%$ de peptona. Os meios de cultivo estéreis foram inoculados com a levedura Saccharomyces cerevisiae US-05 de alta fermentação. O inóculo foi preparado em um Erlenmeyer de $250 \mathrm{~mL}$, contendo $150 \mathrm{~mL}$ de meio cultura YPD estéril onde a massa de $0,06 \mathrm{~g}$ de levedura Saccharomyces cerevisiae liofilizada foi assepticamente adicionada e dissolvida através de agitação manual durante $10 \mathrm{~min}$. Ao meio de cultivo estéril foi adicionado $6,66 \%$ (v/v) do inóculo nos reatores e o cultivo foi conduzido durante $96 \mathrm{~h}$ mantido a $26^{\circ} \mathrm{C}$ sem agitação, conforme Bretanha (2013) Os ensaios foram realizados na presença e ausência (controle) de AFLA $B_{1}$ na concentração de $1 \mu \mathrm{g} / \mathrm{mL}$ Nos cultivos onde a micotoxina foi adicionada realizou-se primeiramente a adição do padrão de AFLA $B_{1}$ nos reatores de forma asséptica, onde o solvente foi evaporado sob corrente de nitrogênio e posteriormente foi realizada a adição do meio estéril. Após, os reatores foram submetidos à agitação em banho ultrassônico a $37 \mathrm{kHz}$ durante 10 min, seguida da adição do inóculo.

Alíquotas foram retiradas assepticamente para acompanhamento da fermentação submersa a cada $24 \mathrm{~h}$ e avaliadas quanto ao $\mathrm{pH}$, concentração proteica, concentração celular e pH. A determinação da concentração celular foi realizada através da medida da densidade ótica do cultivo em espectrofotômetro a $600 \mathrm{~nm}$, onde a absorvância da biomassa é convertida a concentração celular $(\mathrm{mg} / \mathrm{mL})$ através da curva padrão de concentração celular. O método de Lowry (1951) foi utilizado para a quantificação proteica extracelular, cuja reação 
colorimétrica envolve a oxidação dos aminoácidos aromáticos da proteína com o reagente de fenol, utilizando o reagente de Folin Ciocalteau.

Para a avaliação do estresse celular, foi verificada a atividade enzimática da peroxidase, segundo KHAN e ROBINSON (1994), utilizando guaiacol como substrato. A leitura em espectrofotômetro foi realizada a $470 \mathrm{~nm}$ e uma unidade de atividade específica da enzima peroxidase foi definida como a massa de proteína capaz de causar um aumento da unidade de absorvância (ABS) em 0,001 por minuto por mg de proteína.

Os parâmetros cinéticos do crescimento da levedura na presença e ausência da micotoxina foram calculados segundo as Equações 1 e 2.

$$
\begin{aligned}
& \ln X=\ln X_{0}+\mu_{\text {máx }} t \\
& \operatorname{tg}=\ln 2 / \mu_{\text {máx }}
\end{aligned}
$$

\section{RESULTADOS E DISCUSSÃO}

A presença da aflatoxina $B_{1}$ na fermentação submersa utilizando como microorganismo a levedura Saccharomyces cerevisiae acarretou alterações nos parâmetros cinéticos e físico-químicos do cultivo. De acordo com a Tabela 1, não foi possível observar alteração de $\mathrm{pH}$, comportamento este que pode estar associado a manutenção de rotas metabólicas envolvidas na produção de energia e etanol concomitante a produção de ácidos orgânicos, subprodutos da fermentação alcoólica.

Tabela 1 - Acompanhamento do $\mathrm{pH}$ e atividade enzimática específica da peroxidase no cultivo submerso da levedura Saccharomyces cerevisiae

\begin{tabular}{crccc}
\hline \multirow{2}{*}{ Tempo de Fermentação (h) } & \multicolumn{2}{c}{$\mathrm{pH}$} & \multicolumn{2}{c}{ Peroxidase $\left(\mathrm{U} / \mathrm{mg}_{\mathrm{ptn}}\right)$} \\
& Controle & Contaminado & Controle & Contaminado \\
\hline 0 & 6,2 & 6,2 & $0,469 \pm 0,008$ & $0,478 \pm 0,008$ \\
24 & 5,8 & 5,8 & $0,528 \pm 0,032$ & $0,601 \pm 0,009$ \\
48 & 5,6 & 5,6 & $0,515 \pm 0,007$ & $0,561 \pm 0,008$ \\
72 & 5,9 & 5,8 & $0,464 \pm 0,008$ & $0,497 \pm 0,002$ \\
96 & 5,8 & 5,8 & $0,894 \pm 0,010$ & $0,847 \pm 0,018$ \\
\hline
\end{tabular}

Ptn: proteína. Média \pm desvio padrão.

Com a finalidade de comparar os parâmetros cinéticos de crescimento da levedura na presença e ausência da micotoxina, a regressão do logaritmo neperiano das concentrações celulares dos ensaios foi calculada, e a partir da Equação 1 e 2 foram obtidos os resultados de velocidade máxima específica de crescimento $\left(\mu_{\text {máx }}\right)$ e tempo de geração $(\operatorname{tg})$. No cultivo controle o $\mu_{\text {máx }}$ foi $0,0345 \mathrm{~h}^{-1}$, enquanto que no cultivo contendo a micotoxina foi $0,0398 \mathrm{~h}^{-1}$. O aumento de $15 \%$ na velocidade específica máxima de crescimento no cultivo contaminado pode indicar uma tentativa de eliminar a toxicidade causada pela micotoxina no meio. Desse 


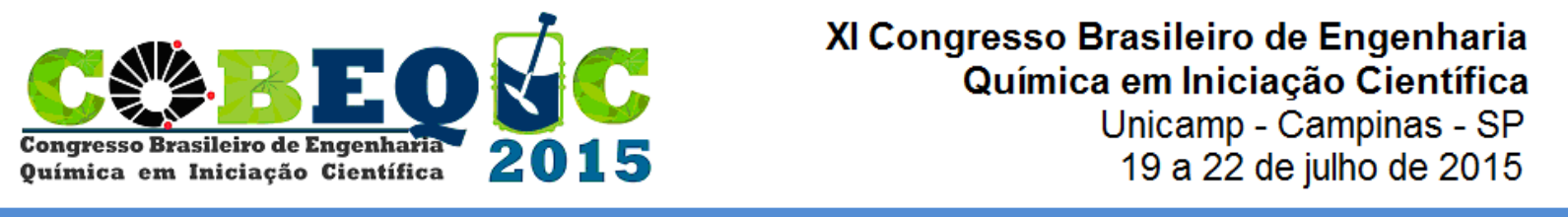

modo, o tempo de geração do cultivo contaminado é menor que o do ensaio controle, sendo eles de 17,9 e $20,1 \mathrm{~h}$, respectivamente.

A Figura 1 apresenta o perfil do conteúdo de proteínas extracelulares dos cultivos controle e contaminado. Como pode ser observado, a concentração de proteínas no cultivo na presença da micotoxina foi maior durante toda a fermentação, quando comparada ao controle. O maior teor proteico pode estar relacionado a maior produção de enzimas oxidativas no metabolismo da levedura. Como pode ser observado pela Tabela 1, a atividade enzimática específica da peroxidase também foi maior no cultivo contendo AFLA $B_{1}$, principalmente em 48 e 72 h, que corrobora com os resultados obtidos dos parâmetros cinéticos e da concentração de proteínas extracelulares, reforçando a possibilidade de estresse celular causado pela micotoxina e consequentemente a ativação de rotas metabólicas secundárias na tentativa de eliminação da toxicidade do meio e manutenção da viabilidade celular.

Figura 1 Perfil do teor proteico extracelular em cultivos submersos utilizando Saccharomyces cerevisiae

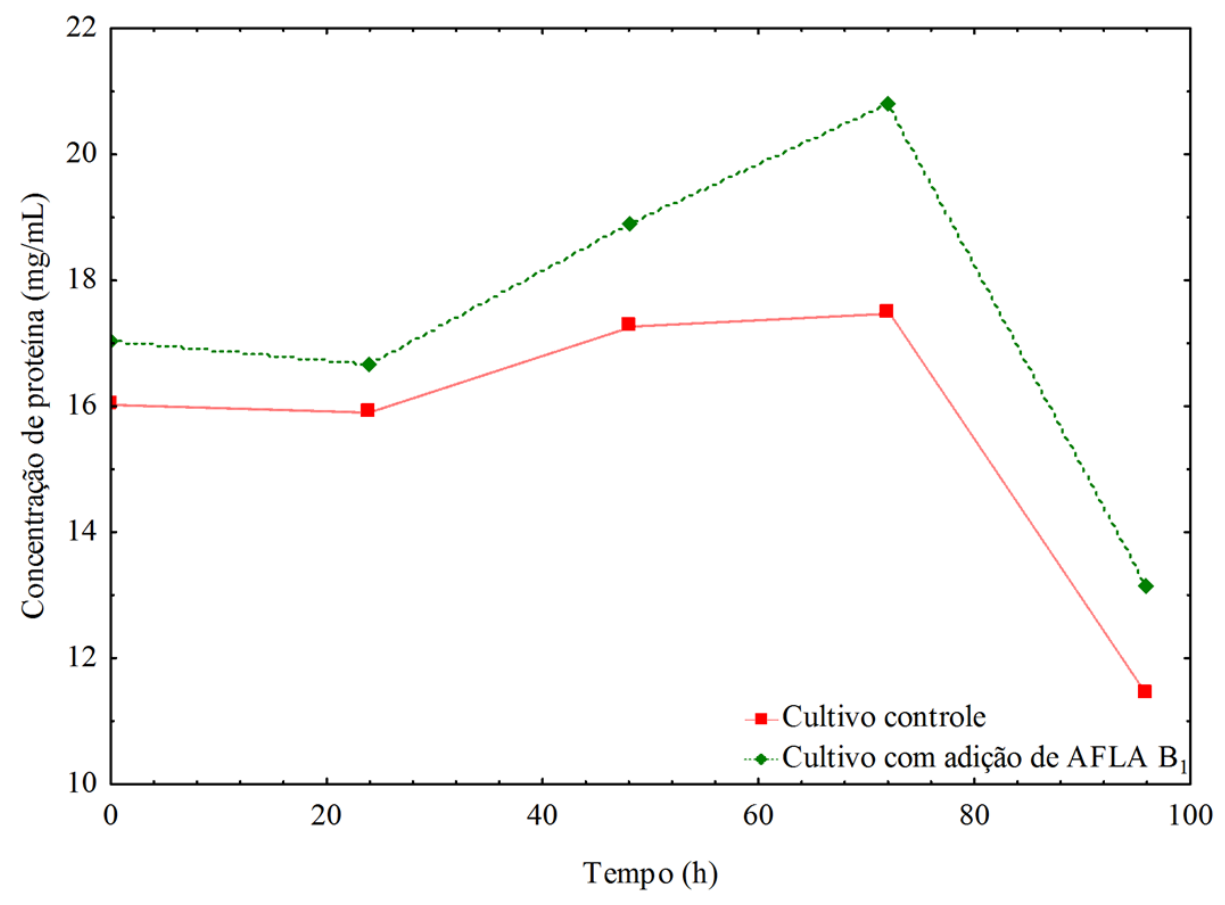

A concentração de proteínas de uma célula pode ser considerada como parâmetro de avaliação de manifestação gênica, e colaborar na elucidação de ciclos metabólicos quando processos de toxicidade celular estão envolvidos (ANDERSON, MATHESON e STEINER, 2000). A concentração de proteínas extracelulares apresentou maior alteração no conteúdo em $72 \mathrm{~h}$ de cultivo, sendo 19\% superior na presença da micotoxina. Esta pode ser uma resposta da célula da levedura em função da toxicidade do meio de cultivo ou mesmo na utilização da estrutura da micotoxina como fonte de nutriente. 


\section{CONCLUSÃO}

A fermentação alcoólica em cultivo submerso da Saccharomyces cerevisiae na presença da micotoxina AFLA $B_{1}$ propiciou um aumento na velocidade específica de crescimento de $15 \%$. O teor de proteínas extracelulares foi $19 \%$ superior no cultivo contaminado em $72 \mathrm{~h}$ de cultivo, corroborando com os valores da atividade enzimática específica da peroxidase que apresentaram maiores valores quando a levedura foi exposta à micotoxina.

\section{NOMENCLATURA}

$\begin{array}{llc}\text { X } & \text { Concentração de células } & \mathrm{mg} / \mathrm{mL} \\ \mathrm{X}_{0} & \text { Concentração inicial de células } & \mathrm{mg} / \mathrm{mL} \\ \mathrm{t} & \text { Tempo } & \mathrm{h} \\ \mathrm{tg} & \text { Tempo de geração } & \mathrm{h} \\ \mu_{\text {máx }} & \text { Velocidade específica máxima de crescimento } & \mathrm{h}^{-1}\end{array}$

\section{REFERÊNCIAS}

ANDERSON, N. L. D MATHESON, A. D.; STEINER, S. Proteomics: applications in basic and applied biology. Protein technologies and commercial enzymes, v.11, p. 408-412, 2000.

BRASIL. Resolução RDC n 7 de 22 de fevereiro 2011. Agência Nacional de Vigilância Sanitária (ANVISA). Disponível em $<$ http://www.micotoxinas.com.br/legisla.html >. Acesso em 25 jan. 2015.

BRETANHA, C. C.; Caracterização de cultivo submerso com Saccharomyces cerevisiae para produção de biomarcadores micotoxicológicos. Dissertação (Programa de PósGraduação em Engenharia e Ciência de Alimentos) - FURG. 2014.

BOLECHOVÁ, M.; BONEŠOVAÁ, K.; BĚLÁKOVÁ, S.; ČÁSLAVSKÝ, J.; POSPÍCHALOVÁ, M.; MIKULÍKOVÁ, R.; Determination of seventeen mycotoxins in barley and malt in the Czech Republic. Food Control, v. 47, p-108-113, 2015.

CARÃO, A. C. P.; BURBARELli, M. F. C.; POLYCARPO, G. V.; SANTOS, A. R. de; ALBUQUERQUE, R. de; OLIVEIRA, C. A. F. de; Métodos físicos e químicos de detoxificação de aflatoxinas e redução da contaminação fúngica na cadeia produtiva avícola. Ciência Rural, v. 44, n. 4, Santa Maria, 2014.

FLORES, J. C. J.; Produção de biomarcadores para deoxinivalenol por Saccharomyces cerevisiae em cultivo submerso. Dissertação (Programa de Pós-Graduação em Engenharia e Ciência de Alimentos) - FURG. 2013. 
GARDA, J.; MACEDO, R. M.; FARIA, R.; BERND, L.; DORS, G. C.; BADIALEFURLONG, E.; Alcoholic fermentation effects on malt spiked with trichothecenes. Food Control, v. 16, p-423-428, 2005.

KHAN, A. A.; ROBINSON, D. S. Hydrogen donor specificity of mango isoperoxidases. Food Chemistry, v. 49, n. 4, p. 407-410, 1994.

KLOSOWSKI, G.; MIKULSKI, D.; The effect of raw material contamination with mycotoxins on the composition of alcoholic fermentation volatile by-products in raw spirits. Bioresource Technology, v. 101, p. 9723-9727, 2010.

LOWRY, O. H.; ROSENBROUGH, M. J.; FARR, A. L.; RANDALL, R. J. Protein measurement with the Folin Phenol Reagent. Journal of Biological Chemistry, v. 193, p. 265-275, 1951.

MALLMANN, C. A.; SANTURIO, J. M.; WENTZ, I.; Aflatoxinas - Aspectos clínicos e toxicológicos em suínos. Ciência Rural, Santa Maria, v. 24, n.3, p. 635-643, 1994.

OLIVEIRA, C. A.F.; ALBUQUERQUE, R.; CORREA, B.; KOBASHIGAWA, E.; REIAS, T. A.; FAGUNDES, A. C. A.; LIMA, F. R.; Produção e qualidade dos ovos de poedeiras submetidas à intoxicação prolongada com Aflatoxina $\mathrm{B}_{1}$. Arq. Inst. Biol., São Paulo, v.68, n.2, p.1-4, jul./dez., 2001.

RODRÍGUEZ-CARRASCO, Y.;FATTORE, M.; ALBRIZIO, S.; BERRADA, H.; MAÑES, J.; Occurrence of Fusarium mycotoxins and their dietary intake through beer consumption by the European population. Food Chemistry, v. 178, p. 149-155, 2015. 